\title{
Comparison of Simulation and Optimization Possibilities for Languages: DYNAMO and COSMIC \& COSMOS - on a Base of the Chosen Models
}

\author{
Elżbieta Kasperska, Elwira Mateja-Losa, and Damian Słota \\ Institute of Mathematics, \\ Silesian University of Technology, \\ Kaszubska 23, 44-100 Gliwice, Poland \\ \{e.kasperska, e.mateja, d.slota\}@polsl.pl
}

\begin{abstract}
On the base of the chosen models, the comparison of simulation and optimization possibilities for languages DYNAMO and COSMIC \& COSMOS, is presented. The computational techniques, for example: integration facilities, optimization opportunities, are the main point of interest for this comparison.
\end{abstract}

\section{Introduction}

The problem of modelling, simulation and optimization of complex, nonlinear, dynamical and multilevel systems, authors already have undertaken in many papers (see $3,4,5,6,7,8,9,10,11)$. In mentioned works the main attention on the problem of modelling, structure of object, results of experiments, were paid. Now we are concentrating on some technical aspects of realization of these experiments using languages: Professional DYNAMO and COSMIC \& COSMOS [1 13 . The computational techniques, for example: integration facilities, optimization opportunities, are the main point of interest. Specially, two different philosophies of embedding simulation and optimization, will be undertaken. The locally or globally solutions can be confronted with the decision-makers preferences and objectives, giving interesting issues for building, for example, decision support systems.

\section{Some Technical Aspects of Computational Opportunities for Languages: DYNAMO and COSMIC \& COSMOS}

Realization of simulation and optimization experiments on models type System Dynamics $2,3,4,5,6,7,8,9,10,11$ requires special languages and computational techniques. 
Two main problems have occured. The one is connected with integration in simulation computation in models of complex, nonlinear, dynamic and multilevel systems. The second problem is related with two philosophies of, so called, embedding simulation in optimization and vice versa on models type System Dynamics.

The Professional DYNAMO [13] provides two types of integration:

- Euler method,

- Runge-Kutta method.

If the Euler's method is used, attention should be paid to a proper choice of the simulation step.If the Runge-Kutta method is used, the simulation step is automatically partitioned to obtain a solution for a given exactness. The example of using both methods is described in paper [7.

In COSMIC (Computer Oriented System Modelling - Integrated Concept) the main attention is paid on simulation step and delays (different orders). To ensure that instability does not occur from delays, the value of $D T$ should be one quarter of the smallest first order delay or one twelfth of the smallest third order delay duration specified in the model (see [1, pp. 34-35]).

The second technical aspect of computational opportunities of mentioned languages is optimization facilities. COSMOS (Computer - Oriented System Modelling Optimization Software) is a software tool which automatically links a dynamic simulation model to an optimization package. This facility makes it possible to apply powerful optimization techniques to:

- the fine tuning of policies in the model (Direct Optimization),

- sensitivity analysis of the model (Base Vector Analysis),

- simplification of the structure of the model (Simplification),

- exploring the effects of forecasting and forward planning in the model (Planning Horizon).

All of these types of optimization are, so called, simulation embedded in optimization. Different philosophy is the optimization embedded in simulation model type System Dynamics. Generally speaking, locally in structure of the model is embedded the optimized decision rule, which dynamically, during horizon of simulation, is changing the structure of model, giving solution (or pseudosolution [12]) which optimized the chosen objective function. Such embedding, authors already have applied in some models [6, 9].

\section{Comparison of Simulation and Optimization Possibilities}

The scope of the paper not allows to undertaken all interesting aspects of mentioned comparison. Lets concentrate of one of them. The problem of embedding optimization in simulation of System Dynamics models is connected with evolution of structure in these models, and applying "hybrid" ideas. Below the idea of such evolution, in the scheme of the main structure of the computational 


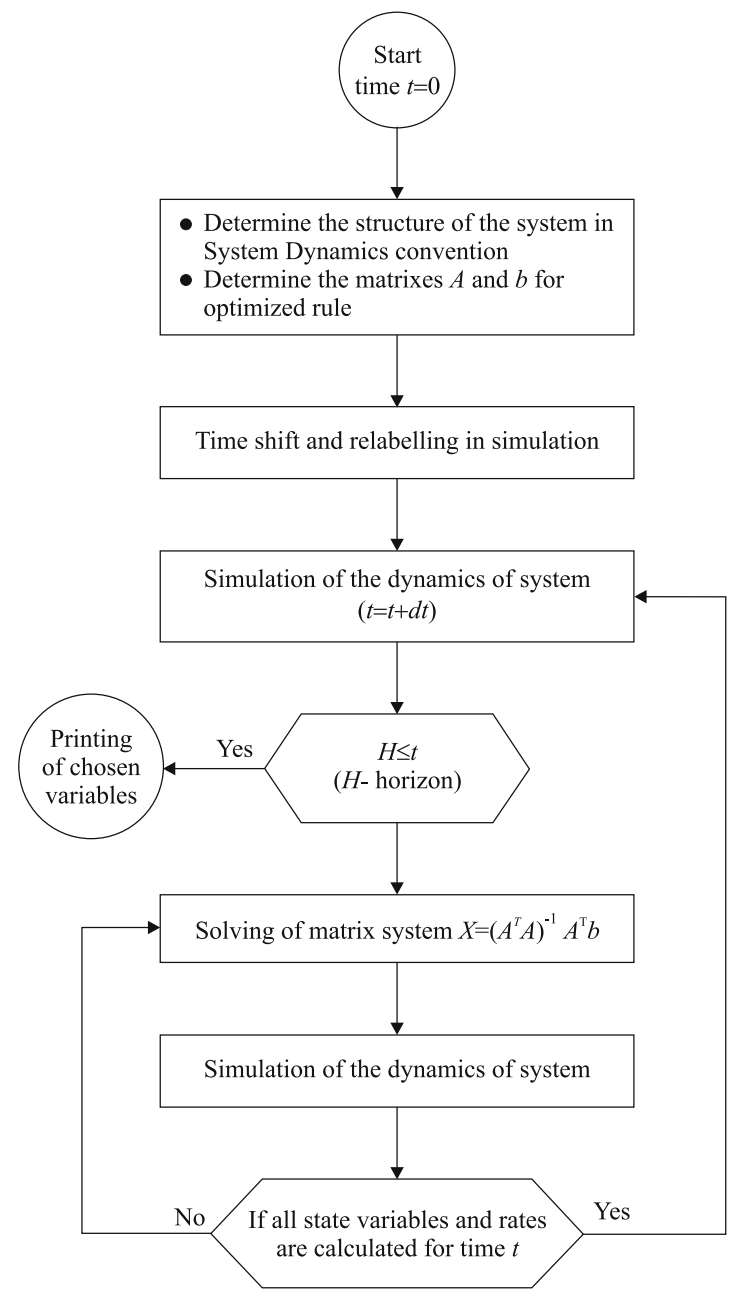

Fig. 1. Block diagram of optimization embedded in simulation on System Dynamics model - on a base of the example of model DYNBALANCE(2-2) 9]

program is presented on Figure 1. For comparison, the block diagram of simulation embedded in optimization on models type System Dynamics is presented on Figure 2 .

Comparing both diagrams, we can see that in first case the achieved solution has locally meaning. Contrary, in second case we have obtained the globally optimized solution. Reminding, that objective function measures interesting aspects of dynamic behaviour of systems (we put attention, our preferences on them), we obtain solution optimal in whole horizon of simulation. Such are the technical possibilities of both computational programs in appropriate languages: DYNAMO and COSMIC \& COASMOS. 


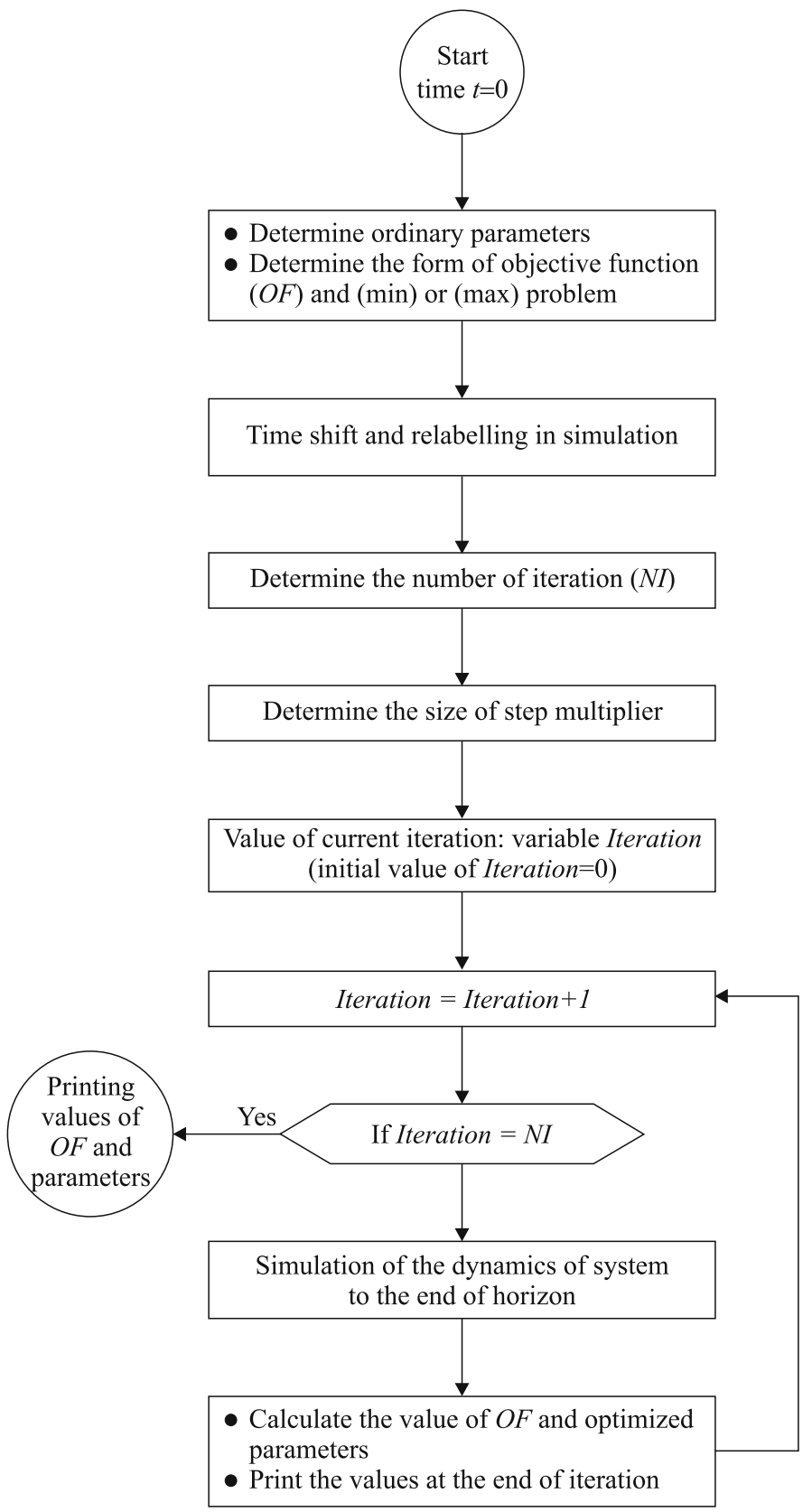

Fig. 2. Block diagram of simulation embedded in optimization on System Dynamics model - on a base of the example of model DYNBALANCE(3-1-III) [8] 


\section{Conclusions}

After presenting some technical aspects of computational opportunities for languages DYNAMO and COSMIC \& COSMOS, illustrated in the previous section, we have come to the following conclusions:

- Both languages: DYNAMO and COSMIC \& COSMOS are specialized for System Dynamics models, but only the second has possibilities that are build in its "philosophical" structure of experiments. The first required embedded specific "hybrid" matrix construction in classical program of System Dynamics models.

- Obtained, in both types of computing, solutions are locally or globally optimized. The simulation experiments allows to examine the effects of such solutions (decisions) on the dynamics of a whole system. This aspect has its connections with directives for building decision support systems (experiments with decision-makers preferences and objectives can help in this problem).

\section{References}

1. Coyle, R.G. (ed.): Cosmic and Cosmos. User manuals. The Cosmic Holding Co, London (1994)

2. Coyle, R.G.: System Dynamics Modelling. A Practical Approach. Chapman \& Hall, London (1996)

3. Kasperska, E., Mateja-Losa, E., Słota, D.: Some extension of System Dynamics method - practical aspects. In: Deville, M., Owens, R. (eds.): Proc. 16th IMACS World Congress. IMACS, Lausanne (2000) 718-11 1-6

4. Kasperska, E., Mateja-Losa, E., Słota, D.: Some dynamics balance of production via optimization and simulation within System Dynamics method. In: Hines, J. H., Diker, V. G. (eds.): Proc. 19th Int. Conf. of the System Dynamics Society. SDS, Atlanta (2001) 1-18

5. Kasperska, E., Mateja-Losa, E., Słota, D.: Optimal dynamical balance of raw materials - some concept of embedding optimization in simulation on system dynamics models and vice versa. In: Davidsen, P. I., Mollona, E. (eds.): Proc. 20th Int. Conf. of the System Dynamics Society. SDS, Palermo (2002) 1-23

6. Kasperska, E., Słota, D.: Two different methods of embedding the optimization in simulation on model DYNBALANCE(2-2). In: Davidsen, P. I., Mollona, E. (eds.): Proc. 20th Int. Conf. of the System Dynamics Society. SDS, New York (2003) 1-27

7. Kasperska, E., Słota, D.: The Estimation of the Mathematical Exactness of System Dynamics Method on the Base of Some Simple Economic System. In: Bubak, M., Albada, G.D., Sloot, P.M.A., Dongarra, J.J. (eds.): Computational Science, Part II. LNCS 3037, Springer-Verlag, Berlin (2004) 639-642

8. Kasperska, E., Mateja-Losa, E.: Simulation embedded in optimization - a key for the effective learning prosess in (about) complex, dynamical systems. In: Sunderam, V.S., Albada, G.D., Sloot, P.M.A., Dongarra, J.J. (eds.): Computational Science, Part III. LNCS 3516, Springer-Verlag, Berlin (2005) 1040-1043

9. Kasperska, E., Słota, D.: Optimization embedded in simulation on models type System Dynamics - some case study. In: Sunderam, V.S., Albada, G.D., Sloot, P.M.A., Dongarra, J.J. (eds.): Computational Science, Part I. LNCS 3514, Springer-Verlag, Berlin (2005) 837-842 
10. Kasperska, E.: Some remarks about chosen structural aspect of System Dynamics method. In: 6 éme Congrés Européen de Science des Systémes, AFSCET, Paris (2005) 1-5

11. Kasperska, E., Mateja-Losa, E., Słota, D.: Multicriterion choices in System Dynamics - some way of modelling and simulation. In: 6 éme Congrés Européen de Science des Systémes, AFSCET, Paris (2005) 1-6

12. Legras, J.: Methodes et Techniques De'Analyse Numerique. Dunod, Paris (1971)

13. Pugh, A.L. (ed.): Professional Dynamo 4.0 for Windows. Tutorial Guide. PughRoberts Associates, Cambridge (1994) 